\title{
HOW ADVERTISING AVOIDANCE AFFECTS VISUAL ATTENTION AND MEMORY OF ADVERTISEMENTS
}

\author{
Lucian-Florin ONIȘOR (i)*, Daniela IONIȚĂ (i) \\ Marketing Department, The Bucharest University of Economic Studies, Bucharest, Romania
}

Received 19 January 2020; accepted 29 January 2021

\begin{abstract}
Understanding how to more effectively advertise is an important area for practitioners, many of whom are struggling to stay in business. Nowadays, both product and corporate branding are important and given the increase in online advertising, additional research to better understand advertising avoidance is needed. Most advertising avoidance studies to date measure either task attention or attention to advertising. This paper contributes to a more holistic view of attention by examining two distinct online tasks, such as reading information and buying products, and two forms of advertising, such as product brand advertisements and corporate brand advertisements. An eye-tracking experiment with 121 respondents show that when reading, users look more at advertisements that increase the memory of the ads. Regardless of the task performed, the corporate brand ads are more memorable than the product brand ads even if the product ads attract more attention. The longer the user stays on a website, the more the user will look at the ads and the easier it will be to remember them. However, ads are considered to be distractors for online users, therefore, to increase their effectiveness they must be more engaging and provide value for the audience.
\end{abstract}

Keywords: advertising avoidance, visual attention, memory, corporate branding, eye-tracking, online activities.

JEL Classification: M31, M37, L82.

\section{Introduction}

Advertising is an important tool used by organizations in their marketing communication process. To promote a product, service or idea, advertisers must reach consumers. Worldwide, people spend over six hours per day using the Internet (Kemp, 2019). However, users access Internet for specific purposes and to perform various tasks such as reading, comparing, buying, communicating, sharing, entertaining, or getting informed, they do not go online to watch advertisements. For users, advertisements are distractors that divert their attention from what they want to accomplish. Because attention is a limited resource and stimuli are numerous, users will try to focus only on task-relevant stimuli. Therefore, they

${ }^{\star}$ Corresponding author. E-mail: luciano@ase.ro

Copyright (c) 2021 The Author(s). Published by Vilnius Gediminas Technical University

This is an Open Access article distributed under the terms of the Creative Commons Attribution License (http://creativecommons. org/licenses/by/4.0/), which permits unrestricted use, distribution, and reproduction in any medium, provided the original author and source are credited. 
will ignore advertisements, a phenomenon called advertising avoidance. Advertising avoidance is not a recent issue as it was observed and researched for other media types such as magazines, newspapers, radio and television (Speck \& Elliott, 1997).

Many studies have investigated the information processing and navigation behaviors of online users and how they scan web page elements. In general, web pages regardless of their type (corporate web pages, news, search engine results pages, or blogs), are divided into two areas: the content / functional area and the advertising area. Online users have learned from previous experiences that the upper and right (sometimes even the lower) parts of a web page contain advertising information, while the rest of the screen contains the needed information. Moreover, even when advertisements where not placed in the traditional locations, users were able to recognize ads without having to look at them and ignored them (Kuisma et al., 2010; Pernice, 2018).

There are many factors that influence advertising avoidance, but its main predictor is perceived goal impediment (Cho \& Cheon, 2004). When users have clear goals and specific activities to carry out - such as when being on social networking sites, news sites, search engines, or gaming sites - advertising avoidance is high. The problem is that research, that analyzes attention in a holistic way is relatively limited (Lo et al., 2014). Most research papers focus on either task attention - how attention is distributed on the content page when performing various tasks - or attention on advertising - how attention is captured by different ad features (Hsieh \& Chen, 2011). Few studies analyze the distribution of attention on all areas of the screen when the user performs a specific activity such as reading a text (Kuisma et al., 2010) or searching for something specific (Lo et al., 2014).

It is important to remember that while online is a media context in which advertisement is embedded, such media is accessed by users to "do" something. Aside from the fact that such research is limited, the results also vary: some studies found out that in a reading task $2 \%$ of user's attention was allocated to ads (Kuisma et al., 2010), while other studies found only $0,8 \%$ allocation (Pernice, 2018). While it is true that almost ten years have passed between the two studies the question still remains: is anybody looking anymore? Initially, companies promoted product brands to generate product awareness and preference and to increase the likelihood of being bought. Over the last decades, companies have diversified their advertising strategies and started to also promote their corporate brands due to several benefits such as higher efficiency, increased flexibility, competitive strength, stronger stakeholder engagement and appeal (Lee Yohn, 2016). Moreover, this increased focus on corporate branding will persist in the future (Brexendorf \& Keller, 2017).

From what we have found so far, no study has investigated whether variations occur in the visual attention achieved based on the type of corporate brand used. That is why it is critical to understand how attention is being paid by users according to the task performed (read, compare, select) and distractors (product brand ad versus corporate brand ad). Thus, a relevant research questions is: How much the task and the advertisement type influence advertising avoidance? Based on this, we defined the following objectives: (a) to determine how much attention online users pay to advertisements when reading news versus when buying a product, (b) to find out how memory of advertisements is influenced by the task performed, (c) to examine how much attention product brand ads attract compared to cor- 
porate brand ads, and (d) to establish how memorable product brand ads are compared to corporate brand ads.

The main contribution of this research is that it investigates holistically the way in which online users look at two different types of ads - product brand ads and corporate brand ads when performing two of the most common online activities, namely reading and buying.

The paper is structured as follows. Section 1 reviews the main theories related to key concepts based on which research hypotheses are developed. Section 2 describes the experiment, the participants, the procedure and the measurements made with an eye-tracking device. Section 3 analyses the results, followed by a discussion section which presents the theoretical contributions of this research and suggests some managerial recommendations. Finally, the conclusions, limitations and future research directions are presented.

\section{Theoretical framework}

\subsection{Visual attention, advertising avoidance and memory}

Attention refers to the cognitive process used to identify and select relevant events against competing distractors (Nobre \& Kastner, 2014). Attention is a limited resource, so it is important to understand how it is used. There are two perspectives that explain where we look. The first perspective highlights (Itti \& Koch, 2000) the importance of bottom-up factors. The basic idea is that attention is attracted by salient stimuli that "pop out" from their environment. The viewer will extract features from a scene - such as color, intensity, orientation in a pre-attentive way to build a saliency map, where some regions stand out regardless of their meaning. The second perspective explains the influence of top-down factors and claims that attention will focus on where to capture the most relevant information for the current task (Foulsham, 2015). This top-down attentional control process reveals the importance of variables specific to the viewer, such as the viewer's own mental representations or the goals that the viewer wants to achieve.

For instance, bottom-up factors that draw attention to online ads are the type of ad (text-only vs. text plus picture), the shape (horizontal vs. vertical) and language of the ads (Flores et al., 2014), the ad location (Wedel \& Pieters, 2000), the animation (Kuisma et al., 2010), the taboo level of the message (Myers et al., 2020) and even the facial expression of the models in the ads (Wang et al., 2018). In terms of top-down factors, previous studies suggest that the task goals (Pieters \& Wedel, 2007; Wästlund et al., 2015), the task type or complexity (Betz et al., 2010; Lo et al., 2014; Wang et al., 2014), and the task motivation or involvement (Behe et al., 2015; Huang \& Kuo, 2012; Pieters \& Warlop, 1999) are the most important factors. Even though each type of factors has its own explanatory power, it seems that visual attention is determined by the interplay between top-down and bottom-up influences (Richardson \& Gobel, 2015).

With attention being limited and stimuli being theoretically unlimited, we need a mechanism to select. Selective attention is the ability to focus on what is important to the task at hand while ignoring or suppressing task-irrelevant information. Previous studies have examined when irrelevant stimuli were filtered out. Some theories suggest that from the ini- 
tial phase of perceptual processing of information, there is a filter that selects only relevant stimuli. Other theories argue that all stimuli are processed at perceptual level in the initial phase, but the filtering takes place in the later stages of processing, which explains why sometimes we see, but we do not notice.

Load theory of attention is a hybrid that solves this dispute, accepting that filtering can be done both at the beginning and at the end of the information processing, depending on the type and level of load involved in current processing (Lavie et al., 2004). For example, if the perceptual load in processing relevant stimuli is high, this will reduce distractors interference because attention is limited and is exhausted from the beginning, so there are no resources left for distractors. But if the cognitive load is high (e.g., the person has to switch tasks or performs tasks in parallel) this will increase the interference of distractors.

In a marketing communication context, this selective attention mechanism will generate advertising avoidance, which is defined by Speck and Elliot (1997) as a significant reduction of user exposure to advertising content. The phenomenon was amplified with the emergence of Internet and consumers have started to use ad blocking software and/or to actively avoid looking at ads (Drèze \& Hussherr, 2003; Cho \& Cheon, 2004). Advertising avoidance was highlighted in various contexts, including online gaming (Yeu et al., 2013) sports sponsorship (Alonso Dos Santos et al., 2018) or social media networks (Margarida Barreto, 2013).

It is interesting that, although users avoid looking at ads during online activities, it seems that processing is done at a pre-attentive level and ads still have an impact on their memory (Drèze \& Hussherr, 2003). For advertisers, this is a positive effect: although not seen, their ads were still memorized. However, an experimental study (Duff \& Faber, 2011) shows that some users actually developed a negative attitude towards avoided brands, given that the ads were considered distracting stimuli for a person who is engaged in a focused activity. Still, not all users hold negative attitudes towards advertised brands as other studies suggest. Consumers have both positive and negative beliefs about different brands and this is correlated with brand usage (Winchester \& Romaniuk, 2008; Winchester et al., 2008). Moreover, brand users are more likely to remember seeing those brand ads than non-users (Vaughan et al., 2016).

Memory, is a by-product of attention and is defined as the ability to retrieve past information (Nobre \& Kastner, 2014). While short-term memory has a limited capacity, which means that information is retained for a short duration of time, long term memory can store significant information for an extended period of time. To evaluate memory, recognition (the ability to identify) and recall (the ability to retrieve previous information) tests are used. Still, recognition is considered to be a more powerful method for memory evaluation than recall (Hsieh \& Chen, 2011).

\subsection{Complexity}

Despite its incontestable theoretical merits and huge potential for real-life situations, the attention load theory has been criticized for not defining precisely the cognitive load and how it differed from the perceptual load (Murphy et al., 2016). Therefore, we decided to use and test task complexity as a factor which affects selective attention. Complex tasks can be classified based on attributes such as: multiple pathways to achieve a desired outcome, multiple 
desired outcomes, conflicting interdependencies among paths, and uncertain linkages among paths and outcomes (Campbell, 1988). Considering this typology, there are various tasks ranging from simple to more complex, such as decision tasks, judgment tasks, problem tasks, and fuzzy tasks. We will choose for testing two tasks performed frequently online: reading about an event and choosing/buying a product. Reading a text is a simple task compared to choosing between two competing brands based on specific attributes, which is a decision task. Because attention is limited and selectively allocated to the information most relevant to task (Foulsham, 2015), this means that a simpler task will not consume all attentional resources and, consequently, the user will also look at irrelevant stimuli, such as advertisements, unlike a complex task, where the user will look less at advertisements. Therefore, the first hypothesis is that:

Hypothesis 1. When performing a simple task, the user's attention is allocated more to advertisements than when performing a complex task.

But seeing is not the same as noticing, and there is an important distinction between those two processes (Castel et al., 2015). Seeing is associated with visual attention, while noticing or being aware is more related to memory (Lamme, 2003). According to Castel et al. (2015), memory is often a product of attention, so we will assume that if attention is high, memory will also increase. Thus, the second hypothesis is:

Hypothesis 2. When performing a simple task, the user's short-term memory of advertisements is better than when performing a complex task.

\subsection{Corporate branding}

Users do not access a web page to watch ads. In general, ads represent distractors rather than objects of interest. Studies that have analyzed the extent to which users are looking at advertisements that are embedded within web pages are relatively limited. Such studies have tested advertising effectiveness based on the type of task (Betz et al., 2010) (e.g. free viewing, content awareness, or information search), the type of web page (e.g. text, picture, video based) (Hsieh \& Chen, 2011), or the type and shape of advertisements (horizontal vs. vertical ads) (Flores et al., 2014).

What we are interested in testing product brand advertisements versus corporate brand advertisements embedded in a web page where the user is performing a real task. Corporate branding refers to the practice of promoting the brand name of a corporate entity instead of a product. The process can be traced back to the 1960s (Fetscherin \& Usunier, 2012) and has increased in the last decades due to globalization (Hatch \& Schultz, 2003). Nowadays, marketing is undergoing a paradigm shift towards corporate marketing characterized by an institutional focus. In this context, the corporate brand becomes a valuable resource that can provide a competitive advantage (Balmer \& Gray, 2003). For a corporate brand, visual identity matters and is defined by the corporate name, logo, color and typeface (Dowling, 1994). Other authors add also the slogan as element of the corporate visual identity (Abimbola et al., 2012; Van den Bosch et al., 2005).

This means that a significant difference between a corporate brand ad and a product brand ad is visual complexity. While in the former case, the display ad contains only the 
brand identity elements (name, logo and probably a slogan), in the latter case it contains aside from the brand identity elements - additional text (body text), pictures, and headlines (Pieters \& Wedel, 2007). Visual complexity increases with the number of elements in an object; therefore, product brand ads are more complex than corporate brand ads.

Because there is no on point research, we will elaborate on our hypotheses based on previous studies on online advertising effectiveness. For example, Nielsen and Pernice (2010) argue that graphical ads are less attractive than simple text ads. Other studies (Pieters \& Wedel, 2004) conclude that on the contrary, the pictorial is superior in attracting attention and users are more attracted by the conspicuousness of a product picture, rather than the information conveyed by a product picture (Wu et al., 2016). Recent research suggests that the combination of text and picture attracts more attention but photographs with a single text message attract more than those with multiple text messages (Li et al., 2016). This conclusion seems to be in line with similar studies that reported that users prefer medium complexity banner ads over low or high complexity ones (Kao \& Wang, 2013). It seems that, in general, low complexity ads are ignored while medium complexity ads are more conspicuous, therefore the third hypothesis is that:

Hypothesis 3. Regardless of the type of task performed - simple or complex - product brand ads attract more attention than corporate brand ads.

Since we previously assumed that if attention is high, short-term memory is better, the fourth developed hypothesis is:

Hypothesis 4. Regardless of the type of task performed - simple or complex - product brand ads are more memorable than corporate brand ads.

Previous research show that the way in which a user looks at advertisements is influenced by the level of involvement: consumers saw a high-involvement product as somewhat more appealing if the product was advertised using display ads; however, they saw low-involvement products as slightly more appealing if advertised with text-only ads (Flores et al., 2014). Therefore, it is necessary to clarify whether involvement mediates the relationship between task complexity and attention and memory.

\subsection{Involvement}

A general definition of involvement is a person's perceived relevance of the object based on inherent interests, values, or needs (Behe et al., 2015). Involvement can be assessed from multiple perspectives, such as involvement as an observer (audience) or a participant (actor) (Greenwald \& Leavitt, 1984). The literature reveals that we can measure involvement with different objects (product involvement) or processes (task involvement) - with a context-free scale (Zaichkowsky, 1985, 1994).

Involvement influences the amount of effort involved and leads to different responses. We know, for instance, that highly involved consumers pay more attention to the product and its information (Behe et al., 2015) and involvement promotes a deliberate information search pattern (Huang \& Kuo, 2012). Therefore, involvement should be used to see if it affects the way in which attention is distributed in the online environment. 


\section{Methodology}

\subsection{Experiment overview}

The hypotheses proposed in this study were tested through an eye-tracking laboratory experiment with a $2 \times 2$ factorial design ( 2 levels of task complexity: low and high $\times 2$ levels of ads complexity: product brand ads and corporate brand ads). Task complexity was manipulated by instructing subjects to perform specific tasks: either read about an event or buy a product. For the simple task, the participants had to read a text about an important Romanian historical event (that was commemorated in 2018). For the complex task, the subjects had to compare the characteristics and performance level of two competing smartphones, in terms of twelve dimensions: price, operating system, processor model, dimensions, color, RAM memory, internal memory, type of display, display resolution, video resolution, sensors and number of SIM slots. Buying a product is a decision task more complex than free reading about an event, because the user has to determine which performance configuration represents the best one. According to Campbel (1988), choosing an outcome that optimally achieves multiple desired end-states is a more complex task.

We manipulated the level of ads complexity by varying the number of design elements: thus, corporate brand ads contained only brand elements (name, logo and slogan), while product brand ads contained additional text, pictures or headlines. The four brands used in the experiment were large share brands that are well-known from four different domains (food, apparel/footwear, entertainment and culture) and were previously selected by similar respondents. The same brands were used in both cases. For testing, four different web pages were developed: one similar to a news website and one which resembled an e-commerce web page. Both of them had two variants: one with product brand ads and another one with corporate brand ads. All four web pages consisted of two main areas - a task area and an advertising area - and had the same configuration, as seen in Figure 1. The information was displayed on a single screen so that the subjects did not have to scroll on the page.

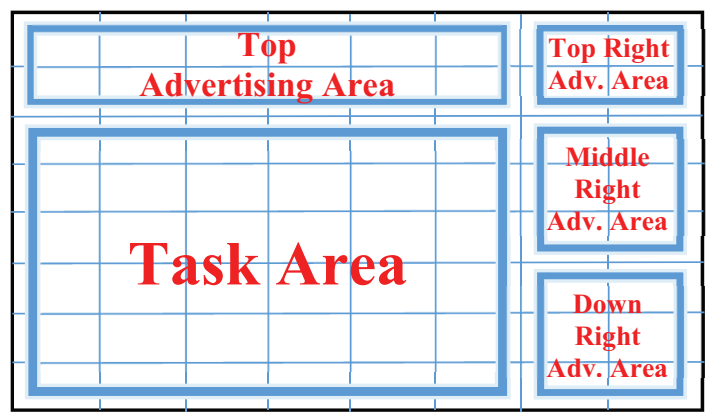

Figure 1. Task and advertising areas on the testing pages

The advertising area was divided into four sub-areas, following Google display ads standards (AdSense, 2017; Statista, 2014) to resemble a real web page: top ( $970 \times 90 \mathrm{px})$, top right $(300 \times 250 \mathrm{px})$, middle right $(336 \times 280 \mathrm{px})$ and down right $(336 \times 280 \mathrm{px})$. Each brand had been placed in the same sub-area, regardless of the website type (with product brand ads 
or corporate brand ads). The rest of the space formed the task area and was used to display information relevant to the task $(1368 \times 697 \mathrm{px})$.

\subsection{Participants}

Participants were selected on a voluntary basis among students from the largest economic university in Romania and were rewarded with credit points. In order to test the hypotheses, we aimed for 30 participants in each experimental group, for a total of 120 respondents. According to previous studies (Kuisma et al., 2010; Nielsen \& Pernice, 2010), at approximately 30 records, the results are stabilized, and additional records do not provide a significant addition of information to change the outcome of the analysis.

To reach the quota of 120 valid records for all groups, it was necessary to test 143 participants. Subjects were randomly distributed to one of the four experimental groups. Thus, the first respondent was allocated to group 11 (task 1 - reading, distractor 1 - corporate brand ads), the second to group 12 (task 1 - reading, distractor 2 - product brand ads), the third to group 21 (task 2 - choosing, distractor 1 - corporate brand ads), the fourth to group 22 (task 2 - choosing, distractor 2 - product brand ads), and so on. From 143 records made, after removing data with calibration errors or experiment misconduct, 121 valid records were retained for analysis. The 121 subjects were between 19 and 22 years old and they belong to the digital natives' generation.

\subsection{Procedure}

At the beginning, participants were informed that the purpose of the experiment was to test attention and that it consisted of several phases, which were explained in detail. At the onset of the experiment, all subjects were informed about the experimental procedure and the eye-tracking device was presented. They were encouraged to ask if they had any questions and they were informed about the possibility to withdraw from the experiment at any time.

The experiment consisted of three test phases. First, subjects responded to a brief questionnaire that measured the degree of involvement in the task they were going to execute. Second, after the calibration of the eye-tracking device, subjects were given instructions to perform a specific task and were warned that some questions would follow afterwards. They were then presented with the web pages, corresponding to the group to which they were assigned, which contained visual stimuli related to task and distractors (ads).

They were allowed to accomplish the tasks received at their own pace. During the third phase, subjects responded to a questionnaire that measured their memory on task and distractors. The experiment lasted between 7 and 12 minutes, with an average of 8 minutes and 46 seconds per participant. During the experiment, the investigator recorded additional details on how the experiment went for each participant into an observation sheet.

\subsection{Measurements}

The dependent variables of the experiment were visual attention and memory. Later on, involvement was tested as a moderator between task complexity/ad complexity and visual at- 
tention/memory. To measure visual attention, we used an eye-tracking device which recorded the number of fixations and the fixation duration time for each area of interest previously defined. These two indicators are commonly used in eye-tracking studies (Holmqvist et al., 2011; Rayner \& Well, 1996; Wątróbski et al., 2017). A higher number of fixations generally indicate that users try to understand the content watched (Poole \& Ball, 2006). Fixations can last a different amount of time. The sum of fixation time is referred to as the total fixation time. Thus, the number of fixations and the duration in which they are made describe the degree of visual attention that a person assigns to the areas that the person is looking at.

Memory was measured at the end of the experiment by filling out a questionnaire with open and close ended questions which covered both the task performed and the ads displayed. Three open questions were used to measure task memory. When processing the answers for each question, we coded the responses in three categories: "correct", "incorrect", and "I don't remember". To prevent guessing, the supplemental information from the observation sheet was used, to filter respondents. Finally, in order to quantify the overall task memory, depending on the answers given to all three questions, a numerical transformation was made for each participant. Those who responded correctly to all three questions received 100 percentage points. Those who responded correctly to two questions out of three, got 66 percentage points, for one correct answer the subjects received 33 percentage points and 0 points for incorrect answers. "I don't remember" answers were treated as incorrect.

For ads memory, five questions were asked: an open-ended question and four closed questions. The open-ended question evaluated recall (subjects were asked to mention all of the brands they remembered seeing on the web page), and the closed questions assessed recognition (we asked subjects to identify from a list the brand displayed in each advertising area). The coding was made in a similar way, with respondents who answered all questions correctly receiving 100 percentage points, those with four correct answers out of five, receiving 80 percentage points, those with three correct answers receiving 60 percentage points and so on. Once again, "I don't remember" answers were treated as incorrect. Involvement with task - reading about a historical event or buying a smartphone - was measured with a 3-item, 7-point semantic differential scale, modified from the last version developed by Zaichkowsky (1994). Due to semantic overlaps of concepts translated in the Romanian language, we decided to use "important", "interesting" and "needed" as dimensions to define involvement. For each respondent involvement was calculated as the mean of values for each dimension.

\subsection{Apparatus and statistical procedure}

The eye tracking device used was the SMI REDn Scientific System from the SensoMotoric Instruments (SMI) company. The recommended manufacturer setting was used, an SMI laptop and an external monitor, both with $1920 \times 1080 \mathrm{HD}$ resolution. The 24 -inch size external monitor was used at $60 \mathrm{~Hz}$ and Image Aspect Ratio was set to 16:9. The investigator sat in front of the SMI laptop and the subjects in front of the stimulus external monitor at a 48 to $87 \mathrm{~cm}$ (average $68 \mathrm{~cm}$ ) distance from the eye tracking sensor. Supplemental keyboard and mouse were provided to participants to use during the experiment. The same brightness conditions were provided through the experiment, for all subjects. 
For the experiment, the software Experiment Center $^{\text {Tw }}$ was used together with the online research platform Lime Survey. Data analysis was done using the SMI BeGaze ${ }^{\mathrm{Tu}}$ and IBMSPSS $^{\mathrm{Tm}}$ software. The design of the test pages was calculated so that each area of interest (task and distractors) fits into the standard gridded AOI of the SMI BeGaze ${ }^{\mathrm{Tm}}$ analysis software of $8 \times 8$ automatic AOI's. Thus, the advertising area was included in the first two horizontal rows and the last three vertical columns. The rest of the space was allocated to the task. Moreover, the automatic gridded $8 \times 8$ AOI facilitated the splitting of the screen in 64 equal AOI that provided a clear delimitation between the task area and the advertising area. Because the AOI's were larger than the visual stimuli investigated (Wang et al., 2018), the areas viewed by the subjects could be clearly distinguished. The data collected for each AOI were divided and summed up accordingly for each exposed area (main, top, top right, middle right and down right). All the validation of the hypothesis tests was performed and the statistical significance of the observed variations was verified in IBM-SPSS ${ }^{\mathrm{m}}$. To test the statistical significance of the obtained results, a series of independent samples T-tests were applied at a 95\% significance level.

\section{Results}

For testing the first hypothesis, participants were divided into two groups: a group of those who carried out the simple task, such as reading a text about a historical event (merger of group 11 \& group 12) and another group made up of those who performed the complex task, such as buying a smartphone by comparing two competing brands (merger of group 21 \& group 22).

Hypothesis 1. When performing a simple task, the user's attention is allocated more to advertisements than when performing a complex task.

Visual attention was measured by the number of fixations and total fixations duration on both the task area and advertising area. The total number of fixations and fixation time (ms.) were converted into percentages and their distribution can be observed in Figure 2. We calculated how attention is distributed between task and distractors by dividing the fixations count on the advertising area (F-AA) or task area (F-TA), to the total number of eye fixations on the page. The same procedure was applied for fixation time: the fixation time on the advertising area (T-AA) or task area (T-TA) was divided to total fixation time.

Attention to advertising area evaluated in average fixations count is 7.0 (3.64\%) when doing a simple task, compared to $5.2(7.04 \%)$ for a complex task, as shown in Figure 2. Considering average fixation time in milliseconds, it is 2959.8 (2.94\%) for a simple task versus $1555.9(3.94 \%)$ for a complex task. There was a significant main effect in the number of fixations to advertising area $[\mathrm{F}(13.754)=2.875, \mathrm{p}<0.005, \mathrm{df}=119]$. If we take into consideration the time allocated to advertising area in both scenarios - simple versus complex task - the differences are not significant $[\mathrm{F}(2.500)=1.086, \mathrm{p}=0.279, \mathrm{df}=119]$. However, based on the average number of fixations (rather than the distribution of attention between task area and advertising area), we concluded that the user's visual attention is allocated more to the advertising area when performing a reading task versus a buying task. Based on these results, the first hypothesis is supported. 


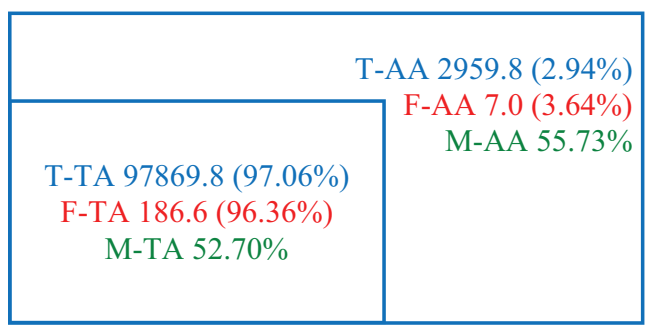

a) Reading

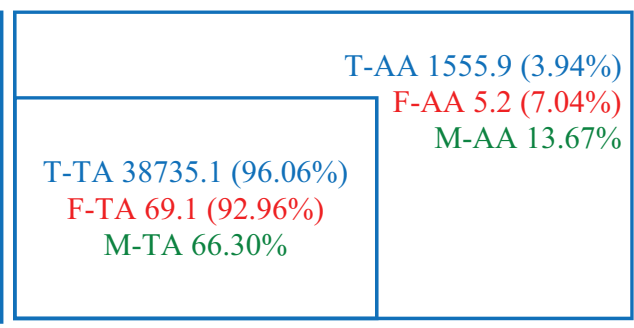

b) Buying

Figure 2. Visual representation of $\mathrm{H} 1$ and $\mathrm{H} 2$ by average fixation Time (T), average Fixation count (F) and short-term Memory (M) on Task Area (TA) and Advertising Area (AA)

To verify the second hypothesis, we maintained the same split of respondents depending on the complexity of the task. For the short-term memory comparison, we used numeric variables obtained from transforming the correct responses attributed to questions about task and advertising.

Hypothesis 2. When performing a simple task, the user's short-term memory of advertisements is better than when performing a complex task.

To assess short-term memory, we asked five questions related to advertising area and three questions related to task. Before running the analysis, we checked the measurement scales for reliability. For advertising memory, five measurements were made: one for recall and four for recognition. Recognition is considered to be a sensitive method for memory evaluation (Hsieh \& Chen, 2011). Reliability analysis indicated 0.852 Cronbach's Alpha coefficient for 5 items scale, which means that the measurements were reliable.

Similarly, we have measured the reliability for the task memory scale, although this type of memory was not the subject of any analysis in our study. Yet those questions were asked only to carry out the experiment naturally and to comfort participants (at the onset of the experiment, participants were instructed to perform a task and answer follow-up questions regarding the task performed). All three questions used were based on recall, even if it is known that recall is a questionable measure of attention (Husić-Mehmedović et al., 2017). Reliability analysis indicated in this case 0.369 Cronbach's Alpha coefficient for 3 items scale, which is not reliable enough. The results for task short-term memory are presented only to preserve data symmetry, but are not used to formulate any conclusions.

Proceeding with the analysis, the averages for each area of interest were calculated and are summarized in Figure 2. Thus, when performing a simple task advertisements memory (55.73\%) scores better than when performing a complex task (13.67\%). The result of independent samples T-tests for the two groups confirms that observed differences are significant [F $(15.940)=-7.931, \mathrm{p}<0.001, \mathrm{df}=119]$. Thus, the second hypothesis is supported.

To examine the third assumption, participants were divided into two groups, based on the type of ads they were exposed to. The first group was formed by those who were presented the corporate brand ads (merger of group 11 \& group 21) and the second group by those who were exposed to product brand ads (merger of group 12 \& group 22).

Hypothesis 3. Regardless of the type of task performed - simple or complex-product brand ads attract more attention than corporate brand ads. 
As described above in the first hypothesis, the same measurements and transformations were made for visual attention, evaluated based on average number of fixations and average fixations duration for the task area and advertising area. No matter how visual attention is measured - either through fixations count or fixation time - product brand ads attract more attention than corporate brand ads, as seen in Figure 3. Thus, in terms of average number of fixations, 6.9 (6.15\%) are allocated to product brand ads compared to 5.3 (4.53\%) for corporate brand ads. Considering average fixation time, product brand ads attract $4.45 \%$ of attention (2995.1 ms.), while corporate brand ads 2.43\% (1647.3 ms.). There was a significant main effect in the fixation time allocated to advertising area $[\mathrm{F}(8.152)=2.495, \mathrm{p}<0.014, \mathrm{df}=119]$.

In contrast to the first hypothesis, this time the differences observed in number of fixations aren't significant $[\mathrm{F}(2.147)=1.484, \mathrm{p}=0.140, \mathrm{df}=119]$, but the differences in term of fixation time are. Based on the second indicator - fixation time - we concluded that users' visual attention is attracted more by product brand ads than corporate brand ads. These results validate the third hypothesis.

Hypothesis 4. Regardless of the type of task performed - simple or complex-product brand ads are more memorable than corporate brand ads.

To test the fourth hypothesis, participants in the experiment were divided into two groups according to the type of ads they were exposed to. The results on memory tests - for task and advertising area - are shown in Figure 3. The scores reveal that corporate brand ads are better memorized compared to product brand ads. The significance tests for the two groups confirm that the differences - for the advertising area - are significant $[\mathrm{F}(1.639)=2.146$, $\mathrm{p}<0.034, \mathrm{df}=119]$. Therefore, the last hypothesis is not supported.

As mentioned in the measurements section, task involvement was measured with a 3-item, 7-point semantic differential scale. Cronbach's Alpha coefficient $=0.812(\mathrm{~N}=121)$, suggests that the scale has reasonable internal consistency, when aggregated across all three conditions. Task involvement differs for reading $(\mathrm{M}=4.20, \mathrm{SD}=1.12, \mathrm{n}=61)$ and buying $(\mathrm{M}=5.25, \mathrm{SD}=1.28, \mathrm{n}=60)$ and this difference is significant $[\mathrm{F}(2.363)=4.778, \mathrm{p}<0.001$, $\mathrm{df}=119]$. Therefore, the buying task is a more involving task than the reading task.

Taking all of these findings into account, a regression analysis was computed to find out if and how task involvement influences advertising short-term memory. Task complexity alone, explains the variation of advertising memory in a proportion of $36.4 \%$ (R Square) with sig-

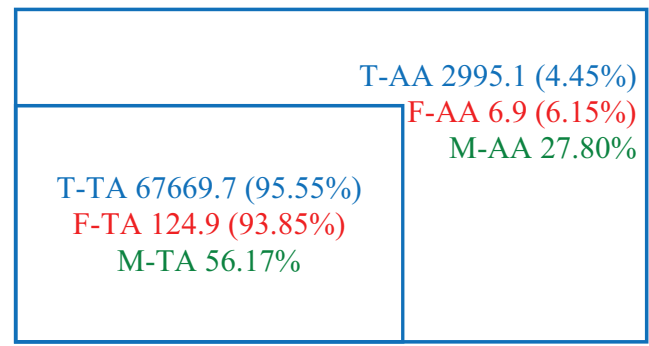

a) Product brand ads

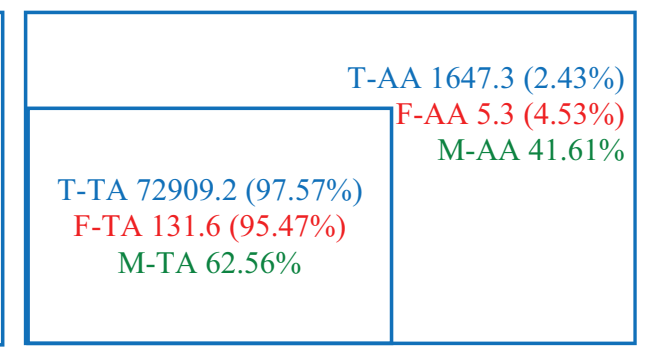

b) Corporate brand ads

Figure 3. Visual representation of $\mathrm{H} 3$ and $\mathrm{H} 4$ by average fixation Time (T), average Fixation count (F) and short-term Memory (M) on Task Area (TA) and Advertising Area (AA) 
nificant Beta coefficient. The involvement is explained by task complexity in a proportion of $16.1 \%$ (R Square) with significant Beta coefficient. By introducing involvement as a mediator for task complexity on advertising memory, we find that the explanation of the regression model could not be increased any more. It remained at $36.4 \%$ and while task complexity Beta coefficient was significant, the involvement Beta coefficient was insignificant.

Similarly, task complexity alone, explains the variation of advertising attention - expressed by fixation count - in a proportion of 6.5\% (R Square) with significant Beta coefficient. By introducing involvement into equation as a mediator for task complexity on advertising attention we find that the explanation of the regression model could not be increased significantly. It goes up to $6.6 \%$ but Beta coefficient was insignificant, so the gain of $0.1 \%$ could not be taken into consideration. For fixation time, the results revealed that advertising attention variation is insignificant. We concluded that task involvement is already quantified in task complexity and does not influence advertising memory or advertising attention. A summary of data regarding the advertising area - calculated distinctly for all four groups - is presented in Table 1.

Table 1. Advertising Area (AA) average Fixation count (F) and short-term Memory (M) averages for all four groups

\begin{tabular}{|l|l|l|}
\hline \multicolumn{1}{|c|}{ Advertising Area } & \multicolumn{1}{|c|}{ Product brand ads } & \multicolumn{1}{c|}{ Corporate brand ads } \\
\hline Reading & F-AA 4.19\% / M-AA 46.00\% & F-AA 3.08\% / M-AA 65.16\% \\
\hline Buying & F-AA $8.11 \%$ / M-AA $8.97 \%$ & F-AA 5.98\% / M-AA $18.06 \%$ \\
\hline
\end{tabular}

Analyzing the four groups using one-way ANOVA, we found that both visual attentionbased on number of fixations $[\mathrm{F}=3.604, \mathrm{p}<0.016, \mathrm{df}=3]$ and memory $[\mathrm{F}=24.931, \mathrm{p}<$ $0.001, \mathrm{df}=3$ ], are significantly different between all the groups.

\section{Discussion}

\subsection{Theoretical contributions}

The purpose of this study was to investigate how task complexity and advertisement type influence advertising effectiveness. Although the results of previous research have revealed a bleak reality, our findings are slightly more optimistic. If we measure visual attention by number of fixations, we find that between $3 \%$ and $8 \%$ of fixations are on the advertising area. Considering the fixation time, the results are slightly different because attention varies between $2 \%$ and $5 \%$. In fact, some researchers anticipate that (Wedel, 2015) advertisers will soon be charged based on how long consumers look at their ads.

Regarding when a user is paying attention to ads, the empirical results are intriguing. Contrary to our expectations, while performing a simple task, users ignored the distractors, which were the ads in this case (3.64\% of fixations). To the contrary, while performing a complex task, users looked more at the distractors (7.04\% of fixations). Similar results (Hsieh \& Chen, 2011) were pointed out by other researchers. They found that a text-reading task is a much heavier workload that occupies more human mental resources than a graph viewing 
task. Therefore, more attention is given to text-reading task, which means that less attention is available to other distractors on a web page. Perhaps the main explanation is the way the information is presented. Text-based web pages crowded with information and organized in a linear way have a lower chance to draw the users' attention to the advertisement area compared to picture-based web pages. However, these results must be interpreted with caution: even if the distribution of attention on the advertising area (as \% of total attention) is lower for a simple task, the number of fixations on that area is in fact higher. This can be explained by the effort required to perform the task. Reading information requires more time and fixations than buying something, which will also increase the time and number of fixations on the rest of the web page, namely the advertising area. Considering what captures user attention, our results indicate that product brand advertisements have a higher ability to attract attention than corporate brand advertisements, which is in line with the initial assumption. Indeed, an ad that contains other elements in addition to brand identity elements - such as text and images - manages to be more conspicuous.

An unexpected result was the relationship between visual attention and memory. Our assumption was that high visual attention leads to better memory. We found that although the visual attention on advertisements was lower (as \% of total attention), when users read, the memory of the ads scored better. This can be explained by the fact that in a reading task, users have a higher number of fixations on ads and this will increase the chances to remember them. Moreover, regardless of task complexity, even if the product brand ads attracted more attention than the corporate brand ads, the memory of the former was much weaker than the memory of the latter.

\subsection{Managerial recommendations}

Our results have important practical implications. According to the Interactive Advertising Bureau, over the last years increased funds were invested in banner ads for desktop and mobile media, and digital ad revenue has exceeded television ad revenue (IAB, 2018). The question is whether it is worth it and the answer seems to be - it depends.

We found that online advertising is effective for reminder campaigns of well-known corporate brands. But advertising is not only about keeping the brand in the consumers' mind, but also about conveying a message. So, how could a message be delivered without the risk of probably being seen but not noticed? And what about low awareness brands?

Since 2003, there were attempts (Lee \& Benbasat, 2003) to shift from a transactional to an engagement approach. Recently, a social networking site introduced an interactive tool which allow users to set their advertising preferences (Haji \& Stock, 2021). It seems that the time of static advertising messages aimed at passive audience is gone. This must be replaced with a new advertising model: advertising as a service (TrendOne, 2018). Brands must be more proactive and aim to surprise consumers, entertain and offer help at the right time and in the right place. It is not about how we can interrupt and stand out. It is more about a context-oriented service conceived to create added value for a target group, or even individual people. 


\section{Conclusions}

The most surprising conclusion is that users who have given the least attention to the advertising area - namely, those who read and were exposed to corporate brand ads - had the best ads memory. On the other hand, those who paid the highest attention to the advertising area - namely, those who bought and saw the product brand ads - had the weakest ads memory. Obviously, we cannot conclude that there is an inverse relationship between visual attention and memory; there may be another explanation. This experiment indicates that although users look less at corporate brand ads or even do not look at all, they manage to identify and remember the brands. It seems that, although attention is not directed towards the ad, minimal and unclear information is gathered through peripheral vision and the stimulus is reconstituted from memory. Which means that brand identity elements are well engraved in the users' memory so that they can reconstruct and remember the brand even if it was not seen. Well-known visual features like product name, logo/symbol, typography, and slogan are anchors in people's mind. Moreover, task type is a better predictor of viewing behavior than task complexity. Even if we assumed that reading was a low-complexity activity when compared to buying, we saw that because it took longer to perform it had increased the chances to look at ads and memorize them.

This study has some limitations. First of all, only two tasks were tested - reading and buying. There are other tasks that are done online by users, but even more accurate would be to investigate a larger segment of activities, namely behaviors. Secondly, we tested two types of web pages that were simulated. Even if simulation was necessary, because we needed to experimentally control certain variables, in real life users do not access only a web page but rather a succession of web pages. They navigate, are dynamic and it is very likely that, when instructed to execute only a task on a single page, they behaved differently than in real life. Thirdly, large share brands that are well-known were used in the current study. We do not know how the results could change for lesser-known brands with lower brand usage, and this opens up some interesting questions for further studies. Finally, we tested corporate brand ads which contained only brand identity elements, such as name, logo and slogan, therefore the visual ad complexity was lower as compared to product brand ads. However, companies may also add pictures or additional text to their corporate brand ads, which would increase the visual complexity and therefore different results could be recorded.

In sum, with few exceptions, the current advertising model seems to have reached its limits. As long as the ads are perceived by users as distractors, they will be avoided. That is why the solution is not how to make them more intrusive or conspicuous but more relevant. To be accepted, ads should no longer be perceived as distractors, but as useful elements which support users in performing their tasks. Future research should support the development of a new advertising model conceived to create added value for the audience. We should have an operational definition of this concept, develop strategic principles, and provide guidelines for delivering a helpful service at the right time and set the metrics needed to assess the effectiveness of this model. 


\section{Author contributions}

LFO and DI conceived the study and were responsible for the design and development of the data analysis. DI was responsible for the literature review while LFO was responsible for managing the experiment, collecting, and analyzing the data. LFO and DI were responsible for data interpretation.

\section{Disclosure statement}

Authors declare no financial, professional, and personal interests from other parties.

\section{References}

Abimbola, T., Trueman, M., Iglesias, O., Abratt, R., \& Kleyn, N. (2012). Corporate identity, corporate branding and corporate reputations. European Journal of Marketing, 46(7/8), 1048-1063.

AdSense. (2017). Guide to ad sizes. https://support.google.com/adsense/answer/6002621?hl=en

Alonso Dos Santos, M., Moreno, F. C., \& Sánchez-Franco, M. J. (2018). Ceguera al patrocinador: Aplicación a carteles de eventos deportivos. Revista de Administração de Empresa, 58(6), 525-536. https://doi.org/10.1590/s0034-759020180602

Balmer, J. M. T., \& Gray, E. R. (2003). Corporate brands: What are they? What of them? European Journal of Marketing, 37(7/8), 972-997. https://doi.org/10.1108/03090560310477627

Behe, B. K., Bae, M., Huddleston, P. T., \& Sage, L. (2015). The effect of involvement on visual attention and product choice. Journal of Retailing and Consumer Services, 24, 10-21. https://doi.org/10.1016/j.jretconser.2015.01.002

Betz, T., Kietzmann, T. C., Wilming, N., \& König, P. (2010). Investigating task-dependent top-down effects on overt visual attention. Journal of Vision, 10(3), 15. https://doi.org/10.1167/10.3.15

Brexendorf, T. O., \& Keller, K. L. (2017). Leveraging the corporate brand: The importance of corporate brand innovativeness and brand architecture. European Journal of Marketing, 51(9/10), 1530-1551. https://doi.org/10.1108/EJM-07-2017-0445

Campbell, D. J. (1988). Task complexity: A review and analysis. Academy of Management Review, 13(1), 40-52. https://doi.org/10.5465/amr.1988.4306775

Castel, A. D., Nazarian, M., \& Blake, A. B. (2015). Attention and incidental memory in everyday settings. In J. M. Fawcett, E. F. Risko, \& A. Kingstone (Eds.), The handbook of attention (pp. 463-484). The MIT Press.

Cho, C.-H., \& Cheon, H. J. (2004). Why do people avoid advertising on the internet? Journal of Advertising, 33(4), 89-97. https://doi.org/10.1080/00913367.2004.10639175

Dowling, G. R. (1994). Corporate reputations: Strategies for developing the corporate brand. Kogan Page.

Drèze, X., \& Hussherr, F.-X. (2003). Internet advertising: Is anybody watching? Journal of Interactive Marketing, 17(4), 8-23. https://doi.org/10.1002/dir.10063

Duff, B. R. L., \& Faber, R. J. (2011). Missing the mark. Journal of Advertising, 40(2), 51-62. https://doi.org/10.2753/JOA0091-3367400204

Fetscherin, M., \& Usunier, J.-C. (2012). Corporate branding: An interdisciplinary literature review. European Journal of Marketing, 46(5), 733-753. https://doi.org/10.1108/03090561211212494

Flores, W., Chen, J.-C. V., \& Ross, W. H. (2014). The effect of variations in banner ad, type of product, website context, and language of advertising on Internet users' attitudes. Computers in Human Behavior, 31, 37-47. https://doi.org/10.1016/j.chb.2013.10.006 
Foulsham, T. (2015). Scene Perception. In J. M. Fawcett, E. F. Risko, \& A. Kingstone (Eds.), The handbook of attention (pp. 257-280). The MIT Press.

Greenwald, A. G., \& Leavitt, C. (1984). Audience involvement in advertising: Four levels. Journal of Consumer Research, 11(1), 581-592. https://doi.org/10.1086/208994

Haji, R., \& Stock, W. G. (2021). User settings for advertising optimization on Facebook: Active customer participation or settings blindness? Telematics and Informatics, 59, 101548. https://doi.org/10.1016/j.tele.2020.101548

Hatch, M. J., \& Schultz, M. (2003). Bringing the corporation into corporate branding. European Journal of Marketing, 37(7/8), 1041-1064. https://doi.org/10.1108/03090560310477654

Holmqvist, K., Nyström, M., Andersson, R., Dewhurst, R., Jarodzka, H., \& Van de Weijer, J. (2011). Eye tracking: A comprehensive guide to methods and measures. OUP Oxford.

Hsieh, Y.-C., \& Chen, K.-H. (2011). How different information types affect viewer's attention on internet advertising. Computers in Human Behavior, 27(2), 935-945. https://doi.org/10.1016/j.chb.2010.11.019

Huang, Y.-F., \& Kuo, F.-Y. (2012). How impulsivity affects consumer decision-making in e-commerce. Electronic Commerce Research and Applications, 11(6), 582-590. https://doi.org/10.1016/j.elerap.2012.09.004

Husić-Mehmedović, M., Omeragić, I., Batagelj, Z., \& Kolar, T. (2017). Seeing is not necessarily liking: Advancing research on package design with eye-tracking. Journal of Business Research, 80, 145-154. https://doi.org/10.1016/j.jbusres.2017.04.019

IAB. (2018). Digital ad spend reaches an all-time high of $\$ 88$ billion in 2017, with mobile upswing unabated, accounting for 57\% of revenue. https://www.iab.com/wp-content/uploads/2018/05/IAB-InternetAdvertising-Revenue-Report-FY-2017-Draft-Media-Alert-v9.pdf

Itti, L., \& Koch, C. (2000). A saliency-based search mechanism for overt and covert shifts of visual attention. Vision Research, 40(10), 1489-1506. https://doi.org/10.1016/S0042-6989(99)00163-7

Kao, C.-T., \& Wang, M.-Y. (2013). The right level of complexity in a banner ad: Roles of construal level and fluency. In S. Yamamoto (Ed.), Lecture notes in computer science: Vol. 8016. Human interface and the management of information. Information and Interaction Design. HIMI 2013. (pp. 604-613). Springer. https://doi.org/10.1007/978-3-642-39209-2_67

Kemp, S. (2019). Digital trends 2019: Every single stat you need to know about the internet. https://thenextweb.com/contributors/2019/01/30/digital-trends-2019-every-single-stat-you-needto-know-about-the-internet/

Kuisma, J., Simola, J., Uusitalo, L., \& Öörni, A. (2010). The effects of animation and format on the perception and memory of online advertising. Journal of Interactive Marketing, 24(4), 269-282. https://doi.org/10.1016/j.intmar.2010.07.002

Lamme, V. A. F. (2003). Why visual attention and awareness are different. Trends in Cognitive Sciences, 7(1), 12-18. https://doi.org/10.1016/S1364-6613(02)00013-X

Lavie, N., Hirst, A., De Fockert, J. W., \& Viding, E. (2004). Load theory of selective attention and cognitive control. Journal of Experimental Psychology: General, 133(3), 339-354. https://doi.org/10.1037/0096-3445.133.3.339

Lee, W., \& Benbasat, I. (2003). Designing an electronic commerce interface: Attention and product memory as elicited by web design. Electronic Commerce Research and Applications, 2(3), 240-253. https://doi.org/10.1016/S1567-4223(03)00026-7

Lee Yohn, D. (2016). Why companies are advertising their master brand. https://hbr.org/2016/03/why-companies-are-advertising-their-master-brand

Li, Q., Huang, Z., \& Christianson, K. (2016). Visual attention toward tourism photographs with text: An eye-tracking study. Tourism Management, 54, 243-258.

https://doi.org/10.1016/j.tourman.2015.11.017 
Lo, S.-K., Hsieh, A.-Y., \& Chiu, Y.-P. (2014). Keyword advertising is not what you think: Clicking and eye movement behaviors on keyword advertising. Electronic Commerce Research and Applications, 13(4), 221-228. https://doi.org/10.1016/j.elerap.2014.04.001

Margarida Barreto, A. (2013). Do users look at banner ads on Facebook? Journal of Research in Interactive Marketing, 7(2), 119-139. https://doi.org/10.1108/JRIM-Mar-2012-0013

Murphy, G., Groeger, J. A., \& Greene, C. M. (2016). Twenty years of load theory - Where are we now, and where should we go next? Psychonomic Bulletin \& Review, 23(5), 1316-1340. https://doi.org/10.3758/s13423-015-0982-5

Myers, S. D., Deitz, G. D., Huhmann, B. A., Jha, S., \& Tatara, J. H. (2020). An eye-tracking study of attention to brand-identifying content and recall of taboo advertising. Journal of Business Research, 111, 176-186. https://doi.org/10.1016/j.jbusres.2019.08.009

Nielsen, J., \& Pernice, K. (2010). Eyetracking web usability. New Riders.

Nobre, A. C., \& Kastner, S. (2014). The Oxford handbook of attention. Oxford University Press. https://doi.org/10.1093/oxfordhb/9780199675111.001.0001

Pernice, K. (2018). Banner blindness revisited: Users dodge ads on mobile and desktop. Nielsen Norman Group.

Pieters, R., \& Warlop, L. (1999). Visual attention during brand choice: The impact of time pressure and task motivation. International Journal of Research in Marketing, 16(1), 1-16. https://doi.org/10.1016/S0167-8116(98)00022-6

Pieters, R., \& Wedel, M. (2004). Attention capture and transfer in advertising: Brand, pictorial, and text-size effects. Journal of Marketing, 68(2), 36-50. https://doi.org/10.1509/jmkg.68.2.36.27794

Pieters, R., \& Wedel, M. (2007). Goal control of attention to advertising: The Yarbus implication. Journal of Consumer Research, 34(2), 224-233. https://doi.org/10.1086/519150

Poole, A., \& Ball, L. J. (2006). Eye tracking in HCI and usability research. In C. Ghaoui (Ed.), Encyclopedia of human computer interaction (pp. 211-219). IGI Global. https://doi.org/10.4018/978-1-59140-562-7.ch034

Rayner, K., \& Well, A. D. (1996). Effects of contextual constraint on eye movements in reading: A further examination. Psychonomic Bulletin \& Review, 3(4), 504-509. https://doi.org/10.3758/BF03214555

Richardson, D. C., \& Gobel, M. S. (2015). Social attention. In J. M. Fawcett, E. F. Risko, \& A. Kingstone (Eds.), The handbook of attention (pp. 349-368). The MIT Press.

Speck, P. S., \& Elliott, M. T. (1997). Predictors of Advertising avoidance in print and broadcast media. Journal of Advertising, 26(3), 61-76. https://doi.org/10.1080/00913367.1997.10673529

Statista. (2014). Share of online advertising viewability worldwide in 2014, by ad size. https://www.statista.com/statistics/373487/advertising-viewability-ad-size/

TrendOne. (2018). Macro-trend: Advertising as a service. https://www.trendone.com/en/trend-universe/ macro-trends/macro-trend-detail/advertising-as-a-service.html

Van den Bosch, A. L., De Jong, M. D., \& Elving, W. J. (2005). How corporate visual identity supports reputation. Corporate Communications: An International Journal, 10(2), 108-116. https://doi.org/10.1108/13563280510596925

Vaughan, K., Beal, V., \& Romaniuk, J. (2016). Can brand users really remember advertising more than nonusers? Testing an empirical generalization across six advertising awareness measures. Journal of Advertising Research, 56(3), 311-320. https://doi.org/10.2501/JAR-2016-037

Wang, Q., Wedel, M., Huang, L., \& Liu, X. (2018). Effects of model eye gaze direction on consumer visual processing: Evidence from China and America. Information \& Management, 55(5), 588-597. https://doi.org/10.1016/j.im.2017.12.003

Wang, Q., Yang, S., Liu, M., Cao, Z., \& Ma, Q. (2014). An eye-tracking study of website complexity from cognitive load perspective. Decision Support Systems, 62, 1-10.

https://doi.org/10.1016/j.dss.2014.02.007 
Wästlund, E., Otterbring, T., Gustafsson, A., \& Shams, P. (2015). Heuristics and resource depletion: Eyetracking customers' in situ gaze behavior in the field. Journal of Business Research, 68(1), 95-101. https://doi.org/10.1016/j.jbusres.2014.05.001

Wątróbski, J., Jankowski, J., Karczmarczyk, A., \& Ziemba, P. (2017). Integration of eye-tracking based studies into e-Commerce Websites evaluation process with eQual and TOPSIS methods. In S. Wrycza \& J. Maślankowski (Eds.), Lecture notes in business information processing: Vol. 300. Information systems: Research, development, applications, education (pp. 56-80). Springer, Cham. https://doi.org/10.1007/978-3-319-66996-0_5

Wedel, M. (2015). Attention research in marketing: A Review of eye-tracking studies. In J. M. Fawcett, E. F. Risko, \& A. Kingstone (Eds.), The handbook of attention (pp. 569-588). The MIT Press.

Wedel, M., \& Pieters, R. (2000). Eye fixations on advertisements and memory for brands: A model and findings. Marketing Science, 19(4), 297-312. https://doi.org/10.1287/mksc.19.4.297.11794

Winchester, M., \& Romaniuk, J. (2008). Negative brand beliefs and brand usage. International Journal of Market Research, 50(3), 355-375. https://doi.org/10.1177/147078530805000306

Winchester, M., Romaniuk, J., \& Bogomolova, S. (2008). Positive and negative brand beliefs and brand defection/uptake. European Journal of Marketing, 42(5/6), 553-570. https://doi.org/10.1108/03090560810862507

Wu, K., Vassileva, J., Zhao, Y., Noorian, Z., Waldner, W., \& Adaji, I. (2016). Complexity or simplicity? Designing product pictures for advertising in online marketplaces. Journal of Retailing and Consumer Services, 28, 17-27. https://doi.org/10.1016/j.jretconser.2015.08.009

Yeu, M., Yoon, H.-S., Taylor, C., \& Lee, D.-H. (2013). Are banner advertisements in online games effective? Journal of Advertising, 42(2-3), 241-250. https://doi.org/10.1080/00913367.2013.774604

Zaichkowsky, J. L. (1985). Measuring the involvement construct. Journal of Consumer Research, 12(3), 341-352. https://doi.org/10.1086/208520

Zaichkowsky, J. L. (1994). The personal involvement inventory: Reduction, revision, and application to advertising. Journal of Advertising, 23(4), 59-70. https://doi.org/10.1080/00913367.1943.10673459 